\title{
Benchmarking of Market Capacity Assessment Methods and Their Application to Digital Products
}

\author{
Azoev G.L. Sumarokova E.V." \\ Institute of Marketing State University of Management, Moscow, Russia \\ *Corresponding author. Email: ev_sumarokova@guu.ru
}

\begin{abstract}
Marketing analyst in his practical work often faces the need to determine the company's market capacity. Capacity measurements are necessary to assess the volume of product sales in the current market environment and, on this basis, to develop a strategy and plan for marketing activities. This is a very popular analytical counting procedure in marketing. However, when implementing it, there are many difficulties that lead to low accuracy of measurements. In practice, most calculations are based on lagging official statistics or expert estimates, which significantly reduces the quality of such estimates.

In this article, the authors have summarized their experience of using various approaches to capacity estimation, which confirmed their relevance and accuracy. A benchmarking of such methods is presented, including a comparison of the sources of information used, the level of accuracy, and the possibility of use for digital products. Taking into account the results of the comparative analysis, the authors suggest ways to modify these methods in relation to assessing the market capacity of new digital products, primarily digital services and games.

One of the areas of such refinement, as our research has shown, is based on special Big Data Mining technologies that allow you to quickly and efficiently "cut out" the target group of consumers of a digital product among Internet users, and technologies for online surveys of representatives of the target group via smartphones.

The relevance of such an assessment in the web space increases every year due to the significant risk of commercial failure of digital products. The presented proposals will reduce the risk of financing and developing digital products that do not have market prospects due to the low market capacity.

The solutions proposed in this article can become an effective tool for filtering and classifying projects that claim to develop digital products.
\end{abstract}

Keywords: market capacity, evaluation method, benchmarking, digital product, big data, online demand

testing, smartphone

\section{INTRODUCTION}

Currently, attempts to assess the market potential of digital solutions are ultimately implemented on the basis of expert assessments, which are highly subjective and always statistically insignificant. As a result, investors (on whom commercialization depends) are very skeptical of this assessment. The authors propose to solve the chronic problem of inaccuracy in assessing the market demand for digital products that are at the pre-project stage, using an arsenal of methods that have confirmed their relevance in the offline market.

For this purpose, authors of the research set three tasks:

- identify the most relevant methods for measuring the market capacity of products sold in the offline space;
- conduct benchmarking of such methods, identify the most appropriate features of digital products and internet environment;

- determine the direction of modification these methods in relation to the designed digital products.

\section{RESEARCH METHODOLOGY}

To correctly assess the market capacity, you need to determine three important parameters: what type of capacity is being evaluated, for what period of time and for what location.

In this regard, it is important to distinguish between two types of market capacity: potential and real. Approaches to their assessment are different.

Potential capacity by most researchers [1], [2], [3], [4], [5], [7] is represented as the maximum possible sales volume, 
when all potential consumers purchase a product based on the maximum possible level of its consumption. Therefore, this is an unattainable amount, if only because not all potential consumers purchase products, and those who purchase them have real budget restrictions. Therefore, calculations of the potential market capacity of a particular product are made in order to determine the strategic prospects for the development of an existing business, assess the possibility of entering a new market and analyze the degree of market saturation.

The real capacity is represented by [2], [4], [6], [7], [8], [9], [10] as the actual (real) sales volume of the analyzed product. In practice, calculating the real capacity (hereinafter, the capacity) presents a certain problem. This is due to the complexity of determining the total sales volume of the product group. In principle, the required volume is equal to the actual demand and can be determined based on statistical data. However, this is not always possible due to the lack of official statistics on all products and a significant "lag" in statistics.

In this article, we will talk about the real market capacity, as the most popular parameter in marketing activities. And for new products - an average forecast of its value (relative to the optimistic and pessimistic forecast).

To get to the description of methods, it is also important to fix the time period for which the capacity is determined (usually a year) and correctly determine the geographical boundaries of the estimated market. The geographical boundaries of the market expand with increasing product uniqueness and complexity. On the other hand, they are narrowed due to poor and expensive communication, short service life and a high degree of product unification. With regard to digital products distributed in the web environment, the issue with the geography of the market being evaluated is easier to solve - consumers can be all connected to the network, and unlimited by a certain geographical location.

\section{RESEARCH RESULT}

Taking into account the comments made, the authors selected six methods for assessing the capacity of the offline market, the experience of using them testifies to their practical usefulness and accuracy, conducted benchmarking and developed modifications focused on digital products.

\subsection{Selection of the most relevant methods for measuring the market capacity of products sold in the offline space}

\subsubsection{Using the purchasing power index}

The method is used to estimate the capacity of individual regional markets when the capacity of the entire market is known. It can be implemented without preliminary field marketing research, since it uses secondary data. Calculations based on the market capacity determination method based on the purchasing power index are made using the following formulas:

$$
\begin{gathered}
\mathrm{Cr}=\mathrm{C} \times \mathrm{IPP}^{\mathrm{PP}} \\
\mathrm{IPP}=\mathrm{A}^{1} \times \mathrm{SDI}+\mathrm{A}^{2} \times \mathrm{SRT}^{2}+\mathrm{A}^{3} \times \mathrm{S}^{\mathrm{P}}
\end{gathered}
$$

where $\mathrm{C}$ - market capacity;

$\mathrm{C}_{\mathrm{r}}$ - capacity of the regional market;

$\mathrm{I}_{\mathrm{PP}}$ - regional market purchasing power index, \%;

$A_{1}, A_{2}, A_{3}$ - coefficients determined by experimental and statistical methods based on information about purchases of consumer goods in a given region, $\%$;

$\mathrm{S}_{\mathrm{DI}}, \mathrm{S}_{\mathrm{RT}}, \mathrm{S}_{\mathrm{P}}$ - shares of disposable income, retail turnover and the population of the region, respectively, in the disposable income, retail turnover and population of the national market.

Thus, knowing: the capacity of the Russian market of the research product; the shares of the target region by income, retail turnover and population; and the coefficients (percentages) of income, turnover and population of the region related to consumers of this product - it is possible to estimate the capacity of the regional market. All information for calculations is secondary; its sources are Federal State Statistic Service (Rosstat) and the regional statistics service. Experts are also used for evaluation.

\subsubsection{Calculation based on correction coefficients}

Companies with extensive sales experience in certain regions of the country can use this experience to determine the capacity of other regional markets. To do this, it's need to know with great accuracy the real volume of sales of interest products in one of the regional markets and the main factors that determine sales. In this sense, the method for determining market capacity based on correction coefficients (sales volume reduction coefficients) is similar to the previous one. The difference is that the base is not the entire Russian market, but a separate geographical segment that is familiar to the company. The calculation formula looks like this:

$$
\mathrm{C}=\mathrm{C}_{0} \times \mathrm{K}_{1} \times \mathrm{K}_{2} \times \ldots \times \mathrm{K}_{\mathrm{n}}
$$

where $\mathrm{C}$ - calculated (unknown) capacity of the regional market;

$\mathrm{C}_{0}$ - known capacity of one of the regional markets;

$K_{1}, K_{2}, \ldots, K_{n}$ - the coefficients of reduction of sales.

The calculation method is very popular among both trading firms and manufacturers. For example, a company produces charging devices for gadgets (phones and tablets) in China and sells them on the Moscow market for several years. In the course of a special research of the charging device market, it was found that the main (enlarged) 
factors that ultimately determine the level of sales are the population and average wages in the region. In addition, the level of urbanization is important for non-central regions. In this regard, the company, assessing the capacity of the corresponding market (before entering another region), adjusts the private coefficients of sales reduction as follows:

$\mathrm{K}_{1}$ - coefficient of population reduction calculated as a quotient of the division of the population of the region to the population of Moscow,

$\mathrm{K}_{2}$ - coefficient of reduction of the average salary, calculated as a quotient of the division of the average salary paid in the region to the average salary in Moscow, $\mathrm{K}_{3}$ - coefficient of urbanization, calculated as the proportion of cities with a population of 300 thousand people or more (approximately equal to 0.32 ).

Multiplying all the coefficients gives the total sales conversion coefficients for different regions. A similar calculation scheme can be used for other products when the capacity of one of the regional markets is known.

\subsubsection{Using the research panel index}

The method for determining market capacity based on the research panel index is used by specialized marketing agencies that conduct systematic (wave) sample research of various product markets based on standard samples panels. This is one of the most accurate method.

To calculate the market capacity based on primary marketing information, for example, the sales panel, the following data is required: the total number of retail stores selling the analyzed products $\left(\mathrm{K}_{\mathrm{com}}\right)$; the number of retail stores included in the panel $\left(\mathrm{K}_{\mathrm{P}}\right)$; the period for which data is collected for the panel ( $\mathrm{t}$, months); product balances in the warehouses of each store at the beginning and end of the study period $\left(\mathrm{R}_{\mathrm{i}}^{\mathrm{b}}, \mathrm{R}_{\mathrm{i}}{ }^{\mathrm{e}}\right)$ and sales volume for the same period $\left(\mathrm{S}_{\mathrm{i}}\right)$. The calculation formula looks like this:

$$
\mathrm{C}=\left(\sum_{\mathrm{i}}\left(\mathrm{R}_{\mathrm{i}}^{\mathrm{b}}-\mathrm{R}_{\mathrm{i}}^{\mathrm{e}}\right)+\mathrm{S}_{\mathrm{i}}\right) / \mathrm{K}_{\mathrm{P}} \times 12 / \mathrm{t} \times \mathrm{K}_{\text {com }}, \mathrm{i}=1, \ldots, \mathrm{K}_{\mathrm{P}}
$$

The first factor (the average sales volume of one retail store included in the panel) is the main dynamic characteristic of the panel, its index. If specify the panel index using the $I_{P}$, the formula will take a simpler form:

$$
\mathrm{C}=\left(\mathrm{I}_{\mathrm{P}} \times \mathrm{K}_{\mathrm{com}} \times 12\right) / \mathrm{t}
$$

The accuracy of calculations is ensured by the fact that capacity measurements are made in the months that are typical for the year (the sales volume per month of measurement is approximately equal to the average sales volume for the month, obtained as a quotient of the sales volume per year by 12 months). If the measurements were not carried out in a typical (in terms of sales volume) time interval, for calculations need to know the specific weight of sales in this time interval attributed to annual sales. In a similar way, the market capacity is calculated based on data from the consumer panel. The $\mathrm{C}$ values obtained using the merchant and consumer panels must match. The volume of sales must be equal to the volume of purchases. This is a kind of verification the correctness of calculations.

\subsubsection{Assessment on the basis of consumption norms}

The method is usually used for food products, raw materials and consumables, and is essentially a modification of the method that uses the purchasing power index. When determining the market capacity based on consumption rates in the case of food products, the statistical basis for calculations is the annual consumption rates of goods per inhabitant (Inh) and the total population $\left(\mathrm{P}_{\text {com }}\right)$ :

$$
\mathrm{C}=\mathrm{Inh} \times \mathrm{P} \text { com }
$$

To improve accuracy in determining the consumption rate, the population is usually divided into several groups based on consumption intensity, age groups, territory of residence or other important characteristics for the analyst. And then the required norms are determined (calculated) for each of the groups. With this approach the formula for calculating market capacity has a more general form:

$$
\mathrm{C}=\sum \mathrm{ARC}_{\mathrm{i} \times} \mathrm{P}_{\mathrm{i}}, \mathrm{i}=1, \ldots, \mathrm{k},
$$

$\mathrm{ARC}_{\mathrm{i}}$ - annual rate of goods consumption by one representative from the $\mathrm{i}$-th group of households;

$\mathrm{P}_{\mathrm{i}}$ - the population in the i-th group;

$\mathrm{k}$ - total number of household groups representing the study population.

If the market is represented by consumers of food of a certain age (for example, children, middle-aged people, pensioners), the consumption rate should be adjusted to account for age differences in consumption.

When forming consumer preferences for new consumer goods, consumption norms can change quickly. In these conditions, each measurement of capacity is associated with the need for a special measurement of consumption rates and the number of real customers. This situation is often encountered in the Russian market, where the range of consumer products offered has been expanding quite rapidly in recent years. In these conditions, special field researches are conducted to assess the market capacity. Their goal is to determine three values:

- total number of potential users of the product in each selected group $\left(\mathrm{A}_{\mathrm{i}}^{\mathrm{p}}\right)$

- proportion of actual buyers among the potential users $\left(\mathrm{B}_{\mathrm{i}}^{\mathrm{u}}\right)$,

- monthly consumption rate per real buyer $\left(D_{i}\right)$.

The annual capacity is calculated using a modified formula: 


$$
\mathrm{C}=12 \times \Sigma \mathrm{A}_{\mathrm{i}}^{\mathrm{p}} \times \mathrm{B}_{\mathrm{i}}^{\mathrm{u}} \times \mathrm{D}_{\mathrm{i}}, \mathrm{i}=1, \ldots, \mathrm{k}
$$

To do this, groups of potential users are defined. In the case of food products, these groups may be people of different age groups or people living in certain administrative divisions.

\subsubsection{Calculation using the frequency of purchases and standard spending rates}

This method is used for consumer fast-spending products that are purchased systematically (for example, toothpaste, washing powder, cartridge, etc.). When calculating the capacity of the market based on frequency of purchases and standard expenditure of the item in an information database in addition to the number of potential customers and share real consumers of this product are used: consumption volume in a single treatment for this product (S) - standard-time allowance (20 gr. toothpaste for one tooth cleaning, 150 gr. washing powder for one wash, etc.) and the frequency of circulation (use) per month $\left(\mathrm{F}_{\mathrm{i}}\right)$. The calculation is made using the formula:

$\mathrm{C}=12 \times \Sigma \mathrm{A}_{\mathrm{i}}^{\mathrm{p}} \times \mathrm{B}_{\mathrm{i}}{ }^{\mathrm{u}} \times \mathrm{S} \times \mathrm{F}_{\mathrm{i}}, \mathrm{i}=1, \ldots, \mathrm{k}$

All characteristics with the exception of S, which depends on the product characteristics, are determined as a result of field researches.

\subsubsection{Summing up primary, repeat and additional sales}

This method is used for consumer durables goods. In accordance with the logic of building settlements, all consumers are divided into those who first acquires the product (they form the primary market for sales $-S_{p}$ ), who repeatedly buys a product to replace the old (recurrent or secondary sale $-\mathrm{S}_{\mathrm{r}}$ ) and those who buy second, third, etc. copies of the product in addition to the existing one (additional sales $-\mathrm{S}_{\mathrm{ad}}$ ). Based on this, the total sales volume (market capacity) is determined by summing up primary, repeat and additional sales:

$$
\mathrm{C}=\mathrm{S}_{\mathrm{p}}+\mathrm{S}_{\mathrm{r}}+\mathrm{S}_{\mathrm{ad}}
$$

For each specific company, these sales are distributed over time: repeated and additional sales can only occur if there were primary sales. However, for the market as a whole, all three types of buyers are present at any given time. Therefore, from the point of view of assessing the market capacity, it is important to measure their activity.

Primary sales are a key parameter that determines the expansion of the market boundaries. Their measurement is based on forecasting the number of new consumers of the product (as opposed to existing ones) and the level of their equipment with these products.

Repeat sales are a value derived from primary sales. They mainly depend on how consumers who replace a given product with a new one are distributed by the replacement period. For example, $20 \%$ of consumers replace the product after 2 years of operation, $30 \%$ - after 3 years, and the remaining $50 \%$ - after 4 years. Such distributions can be obtained for specific products based on the analysis of a representative sample of buyers using questionnaires or interviews, and then, after being separated by the corresponding years, are used in the calculation of the $\mathrm{S}_{\mathrm{r}}$.

A simplified approach to determining the volume of repeat sales is possible. The key parameters in this case are: the size of the fleet $(\mathrm{P})$ and the service life of the durable goods $(t)$. In this case, the rate of product retirement is calculated. It is defined as the inverse of the service life (1:t). Thus, the formula has the following form:

$$
\mathrm{S}_{\mathrm{r}}=\mathrm{P} \times(1 / \mathrm{t})
$$

It should be noted, that in the near future the most significant part of the total sales of traditional durable goods (washing machines, refrigerators, microwave ovens, etc.) will be re-sales. This is due to an increase in household equipment with such goods and a decrease in population growth.

Additional sales depend on the growth of consumer's income and the consumer value of the additional product (the need to accumulate inventory). With an increase in income other things being equal: the volume of additional purchases increases provided that there is an economic feasibility (benefit) from the possession (use or operation) of another, two, etc. copies of this product. If you know the percentage of consumer's income that is spent on purchasing additional products or the conditions under which these purchases are made, it is not difficult to determine their value. The amount of initial, repeated, and additional purchases determines the desired market capacity.

\subsection{Benchmarking methods for evaluating the offline market capacity and directions for their modernization for the digital products market}

The presented data of comparative evaluation of methods (Table 1) show a direct correlation between the accuracy of estimates and field marketing research performed to collect the necessary data. It is obvious that the information obtained by field methods (large-scale consumer surveys) is more accurate than official statistics. However, it is important that this also leads to high costs and a longer measurement process period (4-5 weeks).

Therefore, when using the presented methods, a significant role will be played by the selection criteria, which ultimately come down to either choosing an expensive and long process that provides acceptable accuracy, or a cheap and fast one with low accuracy. To prepare marketing 
plans, it is important to focus on the first option, and for preliminary assessments - on the second.

Table 1 Benchmarking methods for estimating offline market capacity

\begin{tabular}{|c|c|c|c|c|c|}
\hline \multirow[b]{2}{*}{ Method using } & \multicolumn{3}{|c|}{ Information sources } & \multirow[b]{2}{*}{ Accuracy } & \multirow[b]{2}{*}{$\begin{array}{c}\text { Possibility of use } \\
\text { for digital } \\
\text { products }\end{array}$} \\
\hline & Rosstat data & $\begin{array}{c}\text { Internal } \\
\text { statistics of the } \\
\text { company }\end{array}$ & $\begin{array}{l}\text { Field } \\
\text { research }\end{array}$ & & \\
\hline Purchasing power index & - & + & - & Low & $+/-$ \\
\hline Correction coefficients & + & + & - & Low & $+/-$ \\
\hline Research panel index & - & - & + & High & - \\
\hline Consumption rate & + & - & + & Medium & $+/-$ \\
\hline $\begin{array}{l}\text { Frequency of purchases and standard } \\
\text { consumption rates }\end{array}$ & + & - & + & High & $+/-$ \\
\hline Primary, repeat, and additional sales & - & - & + & High & - \\
\hline
\end{tabular}

The use of the presented methods for digital products has a number of limitations related to the specifics of the implementation of these products, and primarily with:

- the ability to quickly and unlimited replication;

- instant delivery;

- no repeat purchases;

- possibility to sell additional options.

These features do not allow to fully use these methods (without significant changes). They require significant improvement. And one of the areas of such improvement, as our research has shown, can be associated with the use of two special technologies:

- Big Data Mining, allowing to quickly and efficiently "cut out" the target group of consumers of a digital product among internet users;

- online surveys of buyers via smartphones.

Taking into account the comments made the technology for evaluating the market capacity of a digital product may look like this:

- the criteria for selecting those who are users of the projected digital product from the initial database of internet users are formulated;

- questionnaire is formed for potential user's data, which allows testing the demand (demand for the product); questionnaire is formed in such a way that one of the above methods of calculating capacity can be used based on the results of its processing;

- using a special product telecommunications operator, for example, Beeline (original database more than 40 million people - internet users), sending the push on smartphones a dedicated task force with a request to take an online test of demand for the product (the cost of such services to send 40 thousand smartphones does not exceed 50 thousand rubles);

- with $1 \%$ response from respondents, the generated sample will be sufficient for acceptable measurement results (the statistical error will not exceed $+/-5 \%$ ).

\section{DISCUSSION OF RESULTS}

The main idea of the proposed solutions is to create an original technology for assessing the demand for new digital products, the key priority of which is to "assess from the consumer" (potential consumer) the market prospects of digital products (as opposed to currently used expert assessments and Desk calculations of competitiveness).

Its implementation is aimed at improving the accuracy of demand estimates and reducing the risks of financing the development of digital products based on research of actual information about the behavior of potential consumers on the internet using artificial intelligence technologies.

The proposed solutions are aimed at forming a dynamic behavioral (taking into account the specifics of the internet) assessment of statistically significant target groups, which eliminates the subjectivity of expert assessments, minimizes the measurement error and, on this basis, allows at the initial stages of making a decision on project financing to obtain a more reasonable assessment of its market potential.

\section{CONCLUSIONS}

1. Improving the accuracy of market capacity estimation is directly related to the quality of field quantitative marketing research of product acquisition (consumption). This conclusion applies to both offline and digital products. 
2. This conclusion creates a significant advantage for the construction of methods for evaluating the capacity of digital products, since internet technology allows to conduct consumer marketing research with higher accuracy, lower costs and higher speed.

3. High accuracy of online demand testing can be achieved by more accurately determining the composition of the target (tested) group of potential consumers, which is provided by researching the "traces" of their presence in the web environment.

4. A great help in forming a target group can be provided by working with existing Big data, for example, mobile operators, using artificial intelligence technologies. Such technologies allow you to form accurate samples of potential consumers of a digital product based on machine recognition of behavior in the internet.

5. One of the most convenient technologies for testing a product can be online surveys using smartphones, which can reduce the testing time by 3-4 times, and their cost by 2 times. As a result, the process of determining market capacity will become more accessible to businesses. It can also be used by representatives of small businesses, for which offline demand testing is currently unavailable due to the high cost.

\section{ACKNOWLEDGMENTS}

The reported study was funded by RFBR, project number 20-010-00233.

\section{REFERENCES}

[1] A. Tambiev, Market research to identify the specificity and capacity of the Russian market of organic products, International agricultural journal, 1, 2019, pp. 59-62. DOI: $\underline{10.24411 / 2587-6740-2019-}$ $\underline{11016}$

[2] V. Antonets, N. Nechaeva, K. Abubakirova, Organization of R\&D expenditure management by various participants in the research and development market, Economic analysis: theory and practice, 11(176), 2010, pp.19-31.

[3] G. Azoev, V. Afanasiev [et al.], The "nano" market: from nanotechnology - to nanoproduct / Ed. G. Azoev, Moscow: BINOM, 2011.

[4] G. Azoev, V. Aleshnikova, B. Tokarev, Marketing: mastering the profession: Textbook for universities/ Ed. G. Azoev, Saint Peterburg: Piter, 2018.

[5] L. Geni, Determination of competitive advantage and its impact on marketing performance, International Journal of Economic Research, 14(10), 2017, pp. 389401.

[6] A. Kashirin, Purchasing innovative products or purchasing innovations? Innovation, 5(199), 2015, pp.13-21.

[7] P. Kotler, K. Keller, Marketing Management, Saint Petersburg: Piter, 2015.

[8] E. Kozlovskaya, Yu Radionova, Development of a mechanism for managing innovation strategy and commercialization of innovations on the basis of the cost approach. Scientific and Technical Bulletin of St. Petersburg State Polytechnic University, Economics, 1(211), 2015, pp.111-117.

[9] E. Yakovleva, Analysis of the economic efficiency of innovations on the basis of the cost approach, Creative Economy, 9(11), 2015, pp.1385-1396.

[10] E. Yakovleva, D. Demidenko, Theory and practice of analyzing the economic efficiency of R\&D and intellectual property. Scientific and technical statements of the St. Petersburg State Polytechnic University, Economics, 3(197), 2014, pp.194-206. 